\title{
Presence of Chlamydophila pneumoniae DNA in blood cells is a frequent event in patients with the late stage of primary cutaneous lymphomas and with atopic dermatitis
}

\author{
Bogusław Nedoszytko, Piotr Wierzbicki², Leena Karenko³, Agata Maciejewska-Radomska4, Przemysław Stachewicz², \\ Monika Zabłotna' ${ }^{1}$, Jolanta Gleñ ${ }^{1}$, Liisa Väkevä ${ }^{3}$, Roman J. Nowicki' ${ }^{1}$, Małgorzata Sokołowska-Wojdyło ${ }^{1}$ \\ ${ }^{1}$ Department of Dermatology, Venereology and Allergology, Medical University of Gdansk, Gdansk, Poland \\ ${ }^{2}$ Department of Histology, Medical University of Gdansk, Gdansk, Poland \\ ${ }^{3}$ Department of Dermatology and Allergology, University of Helsinki and Helsinki University Central Hospital, Helsinki, Finland \\ ${ }^{4}$ Individual Specialist Medical Practice, Gdynia, Poland \\ Adv Dermatol Allergol 2018; XXXV (3): 274-279 \\ DOI: https://doi.org/10.5114/ada.2018.76224
}

\begin{abstract}
Introduction: Microbial infection and associated super antigens have been implicated in the pathogenesis of cutaneous T-cell lymphoma (CTCL), and many patients die from complicating bacterial infections. It has been postulated that Chlamydophila pneumoniae (C. pneumoniae) infection may be involved in the pathogenesis of Mycosis fungoides (MF) but published data are limited and controversial.

Aim: To analyze the frequency of (C. pneumoniae) DNA presence in blood samples of lymphoma cases.

Material and methods: Using Q-PCR method we analyzed the presence of DNA in the blood samples obtained from 57 patients with CTCL (55 - mycosis fungoides (MF)/Sézary syndrome (SS), one primary cutaneous anaplastic large cell lymphoma (CD30+) and one NKT cell lymphoma) and 3 patients with cutaneous B-cell lymphomas, and 120 individuals from control groups (40 patients with psoriasis, 40 patients with atopic dermatitis and 40 healthy controls). Results: Chlamydophila pneumoniae DNA was identified in 13 of 55 cases in the MF/SS group (23.6\%), in 1 patient with CD30+ large cell lymphoma and in 1 of 3 patients with B-cell lymphoma. The presence of $C$. pneumoniae was confirmed in 1 of 40 psoriatic patients (2.5\%), in 5 of 40 patients with atopic dermatitis (12.5\%) and in none of 40 healthy individuals. Presence of $C$. pneumoniae DNA in MF patients was strongly associated with disease progression; $r s=0.756 ; p=0.0123$ for groups IA $\rightarrow$ IVB, and was noted more frequently in advanced (III + IV) stages than in early $(I-I)$ stages $(p=0.0139)$. There are no differences in the mean age of MF/SS patients with and without infection.

Conclusions: The presence of C. pneumoniae DNA in the blood cells is a frequent event in late stages of MF/SS and may be explained by Th2 shift and suppression of the immune system during the course of the disease.
\end{abstract}

Key words: Chlamydophila pneumoniae, late mycosis fungoides/Sézary syndrome stages, polymerase chain reaction.

\section{Introduction}

Antigen stimulation by pathogens such as bacteria and viruses has been considered a possible predisposing factor to uncontrolled cell proliferation and development of lymphoid and other neoplastic tissue. Helicobacter pylori precedes the development of gastric B-cell lymphoma, mycoplasma-like organisms and hepatitis C virus have been suggested to be associated with Hodgkin disease and Chlamydia trachomatis infection may associate with rectal and cervical cancer. Although several etiologies have been postulated for mycosis fungoides (MF) and Sézary syndrome (SS), their causes remain unknown. Based on the limited experimental and clinical data, it has been speculated that chronic local antigen stimulation by Staphylococcus aureus as well as Chlamydophila pneumoniae (C. pneumoniae) may play a role in the pathogenesis of cutaneous T-cell lymphoma (CTCL) [1-3]. Chlamydo-

Address for correspondence: Małgorzata Sokołowska-Wojdyło MD, PhD, Department of Dermatology, Venereology and Allergology, Medical University of Gdansk, 7 Dębinki St, 80-210 Gdansk, Poland, phone: +48 602618 195, e-mail: mwojd@gumed.edu.pl Received: 1.02.2017, accepted: 14.04.2017. 
phila pneumoniae is a common intracellular microorganism. Seroepidemiological studies indicate that C. pneumoniae infection is by far the most common human chlamydial infection in different cohorts, with seropositivity in at least $50 \%$ of the general population over the age of 20 [4-10]. But polymerase chain reaction (PCR) studies on asymptomatic healthy adults (more than 1000) had established only $1 \%$ of positivity in nasopharyngeal swabs' specimens [11]. In addition to pneumonia, pharyngitis, bronchitis and asthma C. pneumonia is also associated with arteriosclerosis, lung cancer, multiple sclerosis and Alzheimer's disease [12-18]. Chlamydophila pneumoniae can infect, reside and replicate in various cell types including smooth muscle cells, fibroblasts, endothelial cells, bronchial epithelial cells, keratinocytes as well as various immune cells such as macrophages, lymphocytes and natural killer cells (NK) [19, 20]. It induces the increased release of pro-inflammatory mediators including tumor necrosis factor $\alpha$ (TNF- $\alpha$ ), interleukin 6 and 8 (IL-6, IL-8), basic fibroblast growth factor (bFGF) and up regulates adhesion molecules [21]. Recently it has been suggested that $C$. pneumoniae infection may also stimulate the IL-10 production which down regulates the expression of major histocompatibility complex class I (MHC-I), inhibits apoptosis and increases the longevity of the host cell, enhancing the survival of bacteria itself [22-24]. The role of C. pneumoniae in the etiology of CTCL is controversial. It has been suspected that a localized bacterial infection increases local production of inflammatory cytokines including interferon $\gamma$ (IFN- $\gamma$ ) (critical in immunity and immunopathology of chlamydial infection) and CXCL-10, a cytokine chemo attractive for epidermotropic T lymphocytes [24]. Studies on the growth requirements of the abnormal T lymphocytes in MF/SS lead to the identification of a so-called Sézary cell activation factor (SAF) that stimulates the growth of both malignant and non-malignant T cells. Sézary cell activation factor was originally defined as an inducer of functional IL-2 receptors. It is postulated that a combination of SAF and IL-2 stimulates the propagation of oligoclonal T-cell populations from the peripheral blood mononuclear cells (PBMC) of patients with SS, with approximately one third of those cell clones containing the predominant malignant clone [3, 25]. Using a monoclonal antibody inhibitory for SAF activity Abrams et al. demonstrated that SAF is present in more than half skin biopsies taken from patients with MF [26]. It was also confirmed that SAF determinant is not of eukaryotic origin and is associated with C. pneumoniae bacteria [3]. Sézary cell activation factor is a protein of approximately $30 \mathrm{kDa}$, resembling the C. pneumoniae $T$ cell activation factor originally described by Halme et al. [27]. Abrams et al. confirmed the presence of $C$. pneumoniae DNA and RNA in the skin by PCR and reverse transcription - PCR and by sequence analysis of the PCR products. The authors showed that $C$. pneumoniae antigen expression was associated with active disease and was not found after psoralen and ultraviolet therapy.

\section{Material and methods}

\section{Study and control groups}

In this study 60 patients with skin lymphomas (48 from Poland -30 men and 18 women, mean age: 60.7 \pm 13.5 and 12 from Finland -8 men and 4 woman, mean age: $61.9 \pm 21.6$ ) were included, of whom 57 patients were diagnosed with primary CTCL and 3 patients with primary cutaneous B-cell lymphomas (one follicle-center and two marginal zone lymphomas) according to WHO criteria. The control groups consisted of 40 patients with psoriasis (22 men and 18 women, mean age: $49.3 \pm 14.3$ ), 40 with atopic dermatitis (21 men and 19 women, mean age: $13.8 \pm 7.7)$ and 40 healthy individuals ( 21 men, 19 women, 10 from Finland and 30 from Poland, mean age: $39 \pm 15.0$ ). From the $57 \mathrm{CTCL}$ patients, 55 have MF or SS, 1 patient had primary cutaneous anaplastic large cell lymphoma CD (30+), and one had NK/T cell lymphoma. From 55 MF/SS patients, 20 were in early clinical stages (IA-IIA) and 35 patients were in advanced stages (IIBIVB). Additionally skin biopsies were obtained from $6 \mathrm{MF/}$ SS patients.

\section{Material collection and DNA samples}

From all patients and control groups peripheral whole blood samples (EDTA-K2 (Medlab Products, Raszyn, Poland) were collected and stored at $-80^{\circ} \mathrm{C}$. Additionally from 6 examined patients skin biopsies were collected and stored at $-80^{\circ} \mathrm{C}$. DNA was extracted using Blood Mini or Mini AX Tissue (A\&A Biotechnology, Gdynia, Poland) according to the manufacturer's protocols. Further, DNA was precipitated using common sodium acetate-ethanol technique [1] in a final volume of $20 \mu \mathrm{l}$ and stored at $-20^{\circ} \mathrm{C}$ for further analyses. DNA concentration and purity were assessed by NanoDrop ND1000 (ThermoScientific, Wilmington, DE, USA).

Chlamydophila pneumoniae strain and cell lines of C. pneumoniae TW183 strain was purchased from American Type Culture Collection (ATCC) (Rockville, MD, USA) and stored at $-80^{\circ} \mathrm{C}$. In order to propagate C. pneumoniae for PCR optimization, HELA 229 line (ATCC) cells were infected by TW183 lysate in a 24-cell plate, followed by centrifugation ( $15 \mathrm{~min}, 400 \times \mathrm{G}$ ) and incubated at $37^{\circ} \mathrm{C}$ and $5 \%$ of $\mathrm{CO}_{2}$ for 2 days, according to ATCC protocol. After incubation, cells were harvested and stored at $-80^{\circ} \mathrm{C}$. Presence of $C$. pneumoniae in cells was further confirmed by diagnostic nested-PCR assay (BLIRT-DNA, Gdansk, Poland).

\section{Quantitative polymerase chain reaction analysis}

In order to create a specific quantitative assay for c. pneumoniae detection we checked (BLAST N database) 
15 reference sequences of the C. pneumoniae strains and for diversification C. trachomatis strains and the ompA gene was chosen as a good molecular target for detection and quantification.

\section{Optimization and validation of QPCR assay}

We amplified 805 bp fragment of C. pneumoniae TW183 strain based on following primers: 5'CCGGCCTACAATAAGCATTTAC and 5'GAGCTTCTGCAGTAAGTGACCA. The sequence was confirmed by RFLP method. After purification, the PCR product was cloned into pUC19 plas- mid, followed by propagation in Escherichia coli strain, isolation, purification and spectrophotometric quantification of plasmid. This construct was applied as a positive control for the calibration curve. The primers for QPCR assay were designed using VNTI software (Invitrogen, Life Technologies, Carlsbad, CA, USA): 5'AACAAAGTCTGCGACCATCAATTAC, 5'GGCTGAGCAATGCGGATGTTATCAC. The conditions of PCR reaction: $2 \times$ SybrGreen Supermix (BioRad, Hercules, CA, USA), $170 \mathrm{nM}$ of each primer, $4 \mathrm{mM}$ $\mathrm{MgCl}_{2}$ and $\mathrm{dd}_{2} \mathrm{O}$ were mixed with $2 \mu \mathrm{l}$ of template DNA to a final volume of $17 \mu \mathrm{l}$. QPCR was performed in iCycler

Table 1. Frequency of Chlamydophila pneumoniae DNA in blood samples from patients with various types of lymphomas, psoriasis, atopic dermatitis and healthy control groups

\begin{tabular}{|c|c|c|c|c|c|}
\hline \multirow[t]{2}{*}{ Diagnosis/clinical stage } & \multicolumn{3}{|c|}{ Frequency of Chlamydophila pneumoniae DNA } & \multirow{2}{*}{$\begin{array}{l}\text { I vs. II vs. III-IV } \\
\text { stages }\end{array}$} & \multirow[t]{2}{*}{ Early vs. late stage } \\
\hline & $\begin{array}{l}\text { Polish patients } \\
\quad(n=48)\end{array}$ & $\begin{array}{l}\text { Finnish patients } \\
\quad(n=12)\end{array}$ & $\begin{array}{l}\text { Both patient } \\
\text { groups }(n=60)\end{array}$ & & \\
\hline \multicolumn{6}{|l|}{ MF patients: } \\
\hline IA & $0 / 2$ & $0 / 1$ & $0 / 3(0 \%)$ & $0 / 16(0 \%)$ & \multirow[t]{3}{*}{$1 / 20(5.0 \%)$} \\
\hline IB & $0 / 13$ & $0 / 0$ & $0 / 13(0 \%)$ & & \\
\hline$\| \mathrm{A}$ & $1 / 3$ & $0 / 1$ & $1 / 4(25 \%)$ & $3 / 17(17.6 \%)$ & \\
\hline$\| \mathrm{B}$ & $1 / 11$ & $1 / 2$ & $2 / 13(15 \%)$ & & \multirow{8}{*}{$\begin{array}{c}12 / 35(34.3 \%) \\
p=0.0139\end{array}$} \\
\hline III & $3 / 6$ & $0 / 0$ & $3 / 6(50 \%)$ & $6 / 11(54.5 \%)$ & \\
\hline IVA & $0 / 0$ & $1 / 3^{*}$ & $1 / 3(33 \%)$ & & \\
\hline IVB & $2 / 2$ & $0 / 0$ & $2 / 2(100 \%)$ & & \\
\hline MF summary & & & $9 / 44(20.5 \%)$ & & \\
\hline \multicolumn{5}{|l|}{ SS patients: } & \\
\hline IVA & $0 / 1$ & $0 / 0$ & $0 / 1$ & & \\
\hline IVB & $4 / 5$ & $0 / 5$ & $4 / 10(40 \%)$ & & \\
\hline SS summary & & & $\begin{array}{c}4 / 11(36.4 \%) \\
(\mathrm{MF} \text { vs. SS, NS, } \\
p=0.266)\end{array}$ & & \\
\hline All MF/SS patients & $11 / 43$ (25.6\%) & 2/12 (16.7\%) & $13 / 55(23.6 \%)$ & & \\
\hline c-ALCL (CD30+) & $1 / 1$ & 0 & $1 / 1$ & & \\
\hline NK/T lymphoma & $0 / 1$ & 0 & $0 / 1$ & & \\
\hline All CTCL patients & & & $14 / 57$ (24.5\%) & & \\
\hline $\begin{array}{l}\text { Primary cutaneous B-cell } \\
\text { lymphomas }\end{array}$ & $1 / 3$ & 0 & $1 / 3(33 \%)$ & & \\
\hline All lymphomas & & & $15 / 60(25.0 \%)$ & & \\
\hline \multicolumn{6}{|l|}{ Controls } \\
\hline AD patients & & & & & $5 / 40(12.5 \%)$ \\
\hline Psoriasis patients & & & & & $1 / 40(2.5 \%)$ \\
\hline Healthy individuals & & & & & 0/40 (0\%) \\
\hline
\end{tabular}

Positive results obtained only from skin biopsy material. MF-mycosis fungoides, SS - Sezary syndrome, c-ALCL-cutaneous anaplastic large cell lymphoma, $A D$ - atopic dermatitis. 
and fluorescence data were automatically collected and analyzed by iCycler iQ Optical Software ver. 3.0a (BioRad, Hercules, CA, USA). QPCR conditions were: initial denaturation $-95^{\circ} \mathrm{C} / 3 \mathrm{~min} ; 40 \times\left(95^{\circ} \mathrm{C} / 20 \mathrm{~s}, 65^{\circ} \mathrm{C} / 30 \mathrm{~s}\right.$, $72^{\circ} \mathrm{C} / 20 \mathrm{~s}, 77^{\circ} \mathrm{C} / 5 \mathrm{~s}$-fluorescence reading step). A calibration curve was performed in triplicates using 6 ten-fold dilutions $\left(10^{+8}\right.$ to $\left.10^{+3}\right)$ of pUC19 plasmid DNA containing ompA gene. The slope was $=-3.497$; efficiency $=93.2 \%$ with a correlation coefficient of $R^{2}=0.997$. Dynamic meltcurve analysis and agarose-gel electrophoresis were used for all post-PCR reaction tubes to confirm the size of expected amplicon (147 bp). All reactions containing analyzed DNA were performed in duplicates. If the $\Delta C t$ between replicates was $>0.3$ and/or we found a melting peak with a different melting point $>1^{\circ} \mathrm{C}$ from the expected one, the reactions were repeated. As a method of quantification we chose the relative quantity method and for histographs we applied $\Delta C t$ method, where $\Delta C t=$ (mean $C t$ of analyzed group) - (mean Ct of calibration points).

\section{Statistical analysis}

All statistical analyses were done using the Statistica 8.0 (StatSoft Inc., Tulsa, OK, USA), Pearson and Fisher's exact test. For all statistical tests, we used a comparison related significance level of $p<0.05$.

\section{Results}

The presence of C. pneumoniae DNA was detected in 14 of 57 (24.5\%) CTCL patients and in 1 of 3 patients with B-cell lymphomas (primary cutaneous follicle-center B cell lymphoma). In the CTCL group, positive results were found in 13 of 55 (23.6\%) MF/SS patients and in one patient with CD30 (+) anaplastic large cell lymphoma. Chlamydophila pneumonia was detected only in 1 of 6 analyzed skin biopsies taken from MF/SS patients (Table 1). From the controls, bacterial DNA was present in the blood samples in 1 of 40 (2.5\%) psoriasis patients, in 5 of $40(12.5 \%)$ patients with atopic dermatitis, and in none of 40 healthy individuals. No differences between MF and SS patients were observed $(p=0.266)$. The frequency $C$. pneumoniae DNA in the MF/SS group correlated with disease progression ( $r s=0.756, p=0.0123$, Figure 1). None of 16 samples from MF patients with disease (IA or IB) were positive while C. pneumonia was detected in 3 of 17 (17.6\%) cases in stage IIA or IIB, and in 6 of $11(54.5 \%)$ MF patients in stages III or IV of disease. In SS patients, C. pneumoniae DNA was found in 4 of 11 (36.4\%) patients with stage IVB. Cumulatively in the MF/SS group, C. pneumoniae infection was found in 1 of $20(5.0 \%)$ patients in early clinical stage (IA-IIA) and in 12 of 35 (34.3\%) patients in advanced clinical stage (IIB-IVB). The results were statistically significant ( $p=0.0139)$. No differences in mean age between MF/ SS patients with and without infection were observed (Figure 1).

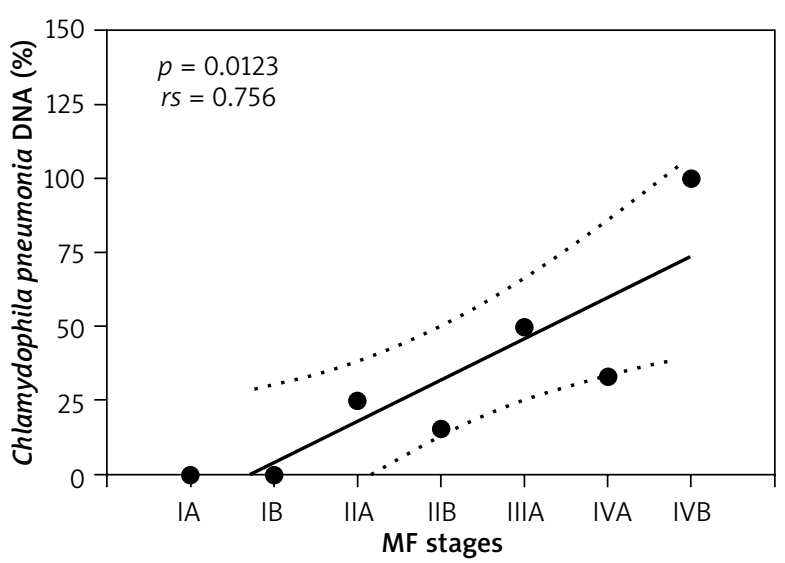

Figure 1. Frequency of Chlamydophila pneumonia in mycosis fungoides/Sezary syndrome patients with different clinical stage of disease

\section{Discussion}

Cutaneous T-cell lymphoma is a malignancy of skin-homing Th1 and/or $\mathrm{Th}_{2} \mathrm{~T}$ cells. A prominent feature of CTCL is immunosuppression, which increases the risk of bacterial and viral infections in patients especially in the advanced stages of disease. The pathophysiology of this immunodeficiency is probably multifactorial. Data from experimental studies suggest that the T-cell repertoire in CTCL patients is significantly contracted [27]. Immunological abnormalities in CTCL are typically associated with depressed ability of peripheral blood cells to produce the Th1 cytokines, IFN- $\gamma$ and IL-2 as a result of Th2 skewing [28-37]. During CTCL progression, reduced T-cell-mediated cellular immune responses and diminished natural killer cell activity also develop [38, 39].

Wysocka et al. have demonstrated a direct relationship between the extent of the pool of circulating malignant T-cells and an impaired immune response [40]. Also the functions of natural killer (NK) cells, including cellular cytotoxicity and production of IFN- $\gamma$, become increasingly impaired as the circulating tumor burden increases. The authors showed an inverse correlation between circulating clonal T cells and activation status of both NK cells and CD8 T cells with a diminishing expression of a number of the activation markers CD69 and CD25, as well as decreased intracellular IFN- $\gamma$ production [40]. The following observations have two main pathophysiological implications. The impaired cellular immune response, which is pivotal for direct antitumor responses, leads to further acceleration of growth of the malignant T-cells population. Another consequence of the decline in cytotoxic T-cell and NK cell functions is impaired activity against opportunistic infectious pathogens. This theory has been supported by the clinical observations [41-43]. It is suggested that the Th2 cytokine pattern may create a permissive environment for C. pneumoniae infection. This concept is supported by few experimental studies 
and clinical observations [44]. Referring to our results, C. pneumoniae DNA was found in $25 \%$ of all patients with CTCL. The frequency of chlamydial infection correlated with the stage of disease. The positive results were seen in $5 \%$ and $34 \%$ of patients with low and high clinical stages of disease, respectively. This observation may confirm the important role of impaired cellular immunological response in the control of opportunistic infections such as C. pneumoniae in CTCL patients. The association between Th1 response impairment and C. pneumoniae infection may be also supported by an increased incidence of bacterial DNA in patients with atopic dermatitis (12.5\%) (Th2 cytokines pattern) vs. psoriatic patients (2.5\%) (Th1 cytokines pattern) and healthy controls (0\%) (immunocompetent individuals). Chlamydophila pneumoniae DNA was detected only in one skin biopsy in our study group, in accordance with the results of German and Italian investigators, who did not detect any bacterial DNA in skin biopsies from MF/SS patients, and confirm that C. pneumoniae infection could not be estimated as a primary triggering factor in the pathogenesis of $\mathrm{CTCL}$, in spite of Casselli et al. who had described skin presence of Chlamydia spp. (and HHV8) in all recurrences of CD30+CTCL as well as in routine control blood samples [45-47].

\section{Conclusions}

Our results suggest that $C$. pneumoniae infection is not a primary event in the pathogenesis of CTCL, but may be estimated as a risk factor complicating advanced stages of the disease associated with Th2 shift and deficiency of antibacterial defence mechanisms.

\section{Acknowledgments}

The study was approved by the local research ethics committee at the Medical University of Gdansk. The study is financed by the Polish Ministry of Science and Higher Education, grant 02-0066/07/253.

\section{Conflict of interest}

The authors declare no conflict of interest.

\section{References}

1. Tan RSH, Butterworth CM, Mclaughlin H, et al. Mycosis fungoides: a disease of antigen persistence. Br J Dermatol 1974; 91: 607-16.

2. Jackow CM, Cather JC, Hearne V, et al. Association of erythrodermic cutaneous T-cell lymphoma, superantigen - positive Staphylococcus aureus and oligoclonal T-cell receptor $V$ beta gene expansion. Blood 1997; 89: 32-40.

3. Abrams JT, Balin BJ, Vonderheid EC. Association between Sezary T-cell activating factor, Chlamydia pneumoniae, and cutaneous T cell lymphoma. Ann N Y Acad Sci 2001; 941: 69-85.
4. Kanamoto Y, Ouchi K, Mizui M, et al. Prevalence of antibody to Chlamydia pneumonia TWAR in Japan. J Clin Microbiol 1991; 29: 816-8.

5. Marton A, Karolyi A, Szalka A. Prevalence of Chlamydia pneumoniae antibodies in Hungary. Eur J Clin Microbiol Infect Dis 1992; 11: 139-42.

6. Montes M, Cilla G, Alcorta M, et al. High prevalence of Chlamydia pneumoniae infection in children and young adults in Spain. Pediatr Infect Dis J 1992; 11: 972-3.

7. Koivisto AL, Isoaho R, Von Hertzen L, et al. Chlamydial antibodies in an eldery Finnish population. Scand J Infect Dis 1999; 31: 153-9.

8. Ni AP, Lin GY, Yang L, et al. A seroepidemiologic study of Chlamydia pneumoniae, Chlamydia trachomatis and Chlamydia psittaci in different populations on the mainland of China. Scand J Infect Dis 1996; 28: 553-7.

9. Ferrari M, Poli A, Olivieri M, et al. Seroprevalence of Chlamydia pneumoniae antibodies in a young adult population sample living in Verona. European Community Respiratory Health Survey (ECRHS) Verona. Infection 2000; 28: 38-41.

10. Freidank HM, Brauer D. Prevalence of antibodies to Chlamydia pneumoniae TWAR in a group of German medical students. J Infect 1993; 27: 89-93.

11. Miyashita N, Niki Y, Nakajima M, et al. Prevalence of asymptomatic infection with Chlamydia pneumoniae in subjectively healthy adults. Chest 2001; 119: 1416-9.

12. Grayston JT, Aldous MB, Easton A, et al. Evidence that Chlamydia pneumoniae causes pneumonia and bronchitis. I Infect Dis 2001; 168: 1231-5.

13. Kuo CC, Jackson LA, Campbell LA, et al. Chlamydia pneumoniae (TWAR). Clin Microbiol Rev 1995; 8: 451-61.

14. Bauriedel G, Andrie R, Likungu JA, et al. Persistence of Chlamydia pneumoniae in coronary plaque tissue. A contribution to infection and immune hypothesis in unstable angina pectoris. Dtsch Med Wochenschr 1999; 124: 1408-13.

15. Fortini A, Corti G, Cappelletti C. Chlamydia pneumoniae and atherosclerosis. Ann Ital Med Int 1999; 14: 253-63.

16. Balin BJHC, Gerard EJ, Arking DM, et al. Whittum-Hudson Identification and localization of Chlamydia pneumoniae in the Alzheimer's brain. Med Microbiol Immunol 1998; 187: 23-42.

17. Budak F, Vahaboğlu H. The investigation of Chlamydophila pneumoniae in patients with multiple sclerosis. Int J Neurosci 2007; 117: 409-15.

18. West SK, Kohlhepp SJ, Jin R, et al. Detection of circulating Chlamydophila pneumoniae in patients with coronary artery disease and healthy control subjects. Clin Infect Dis 2009; 48: 560-7.

19. Rodel J, Woytas M, Groh A, et al. Production of basic fibroblast growth factor and interleukin 6 by human smooth muscle cells following infection with Chlamydia pneumoniae. Infect Immun 2000; 68: 3635-41.

20. Kol A, Bourcier T, Lichtman AH, et al. Chlamydial and human heat shock protein 60 s activate human vascular endothelium, smooth muscle cells and macrophages. J Clin Invest 1999; 103: 571-7.

21. Kaukoranta-Tolvanen SS, Ronni T, Leinonen M, et al. Expression of adhesion molecules on endothelial cells stimulated by Chlamydia pneumoniae. Microb Pathog 1996; 21: 407-11.

22. Caspar-Bauguil S, Puissant B, Nazzal D, et al. Chlamydia pneumoniae induces interleukin-10 production that downregulates major histocompatibility complex class I expression. J Infect Dis 2000; 182: 1394-401. 
23. Geng Y, Shane RB, Berencsi K, et al. Chlamydia pneumoniae inhibits apoptosis in human peripheral blood mononuclear cells through induction of IL-10. J Immunol 2000; 164: 5522-9.

24. Byrne GI, Ojcius DM. Chlamydia and apoptosis: life and death decisions of an intracellular pathogen. Nat Rev Microbiol 2004; 2: 802-8.

25. Sarris AH, Esgleyes-Ribot T, Crow M, et al. Cytokine loops involving interferon-gamma and IP-10, a cytokine chemotactic for CD4+ lymphocytes: an explanation for the epidermotropism of cutaneous T-cell lymphoma? Blood 1995; 86: 651-8.

26. Abrams JT, Vonderheid EC, Kolbe S, et al. Sezary T-cell activating factor is Chlamydia pneumoniae-associated protein. Clin Diagn Lab Immunol 1999; 6: 895-905.

27. Halme S, Saikku P, Surcel HM. Characterization of Chlamydia pneumoniae antigens using human T cell lines. Scand J Immunol 1997; 45: 378-84.

28. Yawalkar N, Ferenczi K, Jones DA. Profound loss of T-cell receptor repertoire complexity in cutaneous T-cell lymphoma. Blood 2003; 102: 4059-66.

29. Hahtola S, Tuomela S, Elo L, et al. Th1 response and cytotoxicity genes are down-regulated in cutaneous T-cell lymphoma. Clin Cancer Res 2006; 12: 4812-21.

30. Okamura H, Tsutsi H, Komatsu T, et al. Cloning of a new cytokine that induces IFN-gamma production by T cells. Nature 1995; 378: 88-91.

31. Naik SM, Cannon G, Burbach GJ, et al. Human keratinocytes constitutively express interleukin-18 and secrete biologically active interleukin-18 after treatment with pro-inflammatory mediators and dinitrochlorobenzene. J Invest Dermatol 1999; 113: 766-72.

32. Yoshimoto T, Takeda K, Tanaka T, et al. IL-12 up-regulates IL-18 receptor expression on T cells, Th1 cells, and B cells: synergism with IL-18 for IFN-gamma production. J Immunol 1998; 161: 3400-7.

33. El-Mezayen RE, Matsumoto T. In vitro responsiveness to IL18 in combination with IL-12 or IL-2 by PBMC from patients with bronchial asthma and atopic dermatitis. Clin Immunol 2004; 111: 61-8.

34. Rook AH, Wood GS, Yoo EK, et al. Interleukin-12 therapy of cutaneous T-cell lymphoma induces lesion regression and cytotoxic T-cell responses. Blood 1999; 94: 902-8.

35. Yoshimoto T, Tsutsui H, Tominaga K, et al. IL-18, although antiallergic when administered with IL-12, stimulates IL-4 and histamine release by basophils. Proc Natl Acad Sci USA 1999; 96: 13962-6.

36. Hwang ST, Janik JE, Jaffe ES, et al. Mycosis fungoides and Sezary syndrome. Lancet 2008; 371: 945-57.

37. Adams AE, Zwicker J, Curiel C. Aggressive cutaneous T-cell lymphomas after TNFalpha blockade. J Am Acad Dermatol 2004; 51: 660-2.

38. Kaplan EH, Rosen ST, Norris DB, et al. Phase II study of recombinant human interferon gamma for treatment of cutaneous T-cell lymphoma. J Natl Cancer Inst 1990; 82: 208-12.

39. Laroche L, Kaiserlian D. Decreased natural-killer-cell activity in cutaneous T-cell lymphomas. N Engl J Med 1983; 308: 101-2.

40. Vowels BR, Cassin M, Vonderheid EC, et al. Aberrant cytokine production by Sezary syndrome patients: cytokine secretion pattern resembles murine Th2 cells. J Invest Dermatol 1992; 99: 90-4.

41. Wysocka M, Zaki MH, French LE, et al. Sezary syndrome patients demonstrate a defect in dendritic cell populations: effects of CD40 ligand and treatment with GM-CSF on den- dritic cell numbers and the production of cytokines. Blood 2002; 100: 3287-94.

42. Axelrod PI, Lorber B, Vonderheid EC. Infections complicating mycosis fungoides and Sezary syndrome. JAMA 1992; 267: 1354-8.

43. Lee J, Richardson S, Melhem ER, et al. Progressive multifocal leukoencephalopathy from JC virus in a patient with advanced mycosis fungoides. J Am Acad Dermatol 2007; 57 : 893-5.

44. Park CS, Kim TB, Moon KA, et al. Chlamydophila pneumoniae enhances secretion of VEGF, TGF-b, and TIMP-1 from human bronchial epithelial cells under Th2 dominant microenvironment. Allergy Asthma Immunol Res 2010; 2: 41-7.

45. Rössler MJ, Rappl G, Muche M, et al. No evidence of skin infection with Chlamydia pneumoniae in patients with $\mathrm{cu}$ taneous T cell lymphoma. Clin Microbiol Infection 2003; 9 : 721-3.

46. Ferreri AJ, Ponzoni M, Govi S, et al. Prevalence of chlamydial infection in a series of 108 primary cutaneous lymphomas. Br J Dermatol 2012; 166: 1121-3.

47. Caselli E, Borghi A, Maritati M, et al. Relapses of primary cutaneous anaplastic large-cell lymphoma in a female immunocompetent patient with persistent Chlamydophila pneumoniae and human herpesvirus 8 infection. Infect Agent Cancer 2016; 11: 31. 